\title{
Redefining smartness in township with Internet of Things \& Artificial Intelligence: Dholera city
}

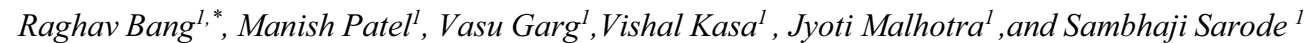 \\ ${ }^{1}$ MIT School of Engineering, MIT ADT University, Pune (MS),India.
}

\begin{abstract}
Internet of Things (IoT) with Artificial Intelligence (AI) has the virtue to address the key challenges encountered by the excessive Urban population; contributing to water management, waste management, energy crisis, and many such affairs. The urban city has reached the level of water scarcity with no adequate water supply. The lack of interconnectivity within the city also leads to severe consequences, such as delayed responses to emergency situations along with irregular traffic and infrastructure management. "Dholera" the futuristic city attempt to solve these issues. Dholera is the biggest and India's first upcoming greenfield smart city solution developed under the Delhi Mumbai Industrial Corridor (DMIC) project in Gujarat, India. We have analyzed a few domains from this township project, to mention a few - Water Management, Waste Management, City Integrated Operation Centre (CIOC) and City portal. This paper spotlights on the novel ideas enhancing the smart city features and the working. Automating the city resources using futuristic technologies like big data analytics, Artificial Intelligence (AI) and the Internet of Things (IoT) would make the city well-functioning. In Dholera city, various sensors are mounted and interconnected to collect the data, monitor it, and communicate the values for dynamic action(s). Dholera has AI-based urban transportation, smart grids, renewable energy, solar power, waste and water management, along with urban farming, contributing to a reduction in carbon dioxide emissions and improving energy, water and managing traffic issues effectively. Smart cities are well classified as the growth bar contributing to the universal economy. This paper presents various models making the Dholera city a Fast Responsive, Sustainable, Intelligent and well-connected township.
\end{abstract}

\section{Introduction}

India is a country with a population of over 1.3 billion [1]. Out of which, over 31.6 percent of people live in urban areas as per the values [2] mentioned in the Fig.1.

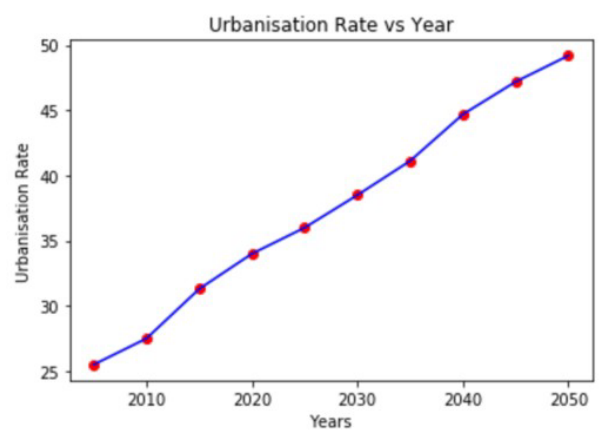

Fig.1. Urbanisation Growth Chart

No one can deny the fact that urbanisation helps in the economy and various other factors of the country but there is a major downside of this growth with sudden increase in the population rate leading to increase in the slum areas and decrease in the standard of living resulting in environmental damage

Despite of many issues that does not results to decrease the growth of urban area, we need to address them by developing the intelligent solutions. For instance, [3] on 28 September 2019, Patna has gone through a drastic rainfall, almost all areas were under knee-deep water and people were struggling to achieve their daily needs. Similarly on 29 August 2017, Mumbai has gone through the same situation. These problems occurred due to poor infrastructure and the lack of technology used in developing the drainage systems. Wastewater in cities is generally pumped into rivers and seas without any filtration leading to pollution, affecting aquatic life and directly damaging the ecosystem. These issues can be addressed or shedded through the smarter solution embarking the construction of smart cities. Smart cities make use of Information and Communication Technology to overcome these problems faced in ordinary cities and increase the standard of living. Using IoT along with Artificial Intelligence can contribute in decision making as IoT helps to collect data via sensors. Smart cities also have

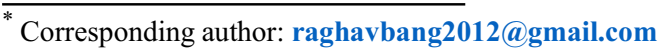


proper infrastructure planning for industrial and residential areas.

Generally, a smart city is classified into two types Greenfield city and Brownfield city. Building a new city from scratch is called Greenfield city and converting existing cities into a smart city is called Brownfield city.

In the wake of this, the Government of India has launched the smart city mission with the aim to develop 100 smart cities and many Greenfield cities across the country making them citizen-friendly and sustainable. One of the cities in the mission is Dholera which is India's first Industrial Greenfield city. Dholera consists of a smart water management system that solves waterlogging and wastewater problems. It also has 4 ICT service centres, which will act as a central hub for all sensors. Supervisory control and data acquisition (SCADA), a computer system for collecting and analysing real-time data makes the city water supply robust. Smart city infrastructure elements includes adequate water supply with smart management and maintenance, assured electricity, proper waste management, efficient urban mobility, and urban transport. Dholera smart city project is divided into 3 phases. Each phase is of 10 years and the deadline for this project is 2042 .

\section{Literature Survey}

This section summarizes the existing methodologies stepped towards smart cities.

Author [4] highlights the purpose of smart cities helping to drive the economic growth and increase the quality of life of people by harnessing the technology that leads to smart outcomes. Individuals are the most important stakeholders in the success of a smart city. It is not necessary that a successful smart city implementation in one country can be replicated in another. The reason is that the people who live in cities have different perspectives and priorities. One way to solve this is to involve people in the process, i.e. - By providing them the engagement platform to reach out to the officials. This way, the citizens will voluntarily suggest what they want in the city and officials can happily accept their suggestions, feedback, and complaints and function accordingly. In this transparent system, citizens will be satisfied with the efficiency of officials and the city administrators will have the opportunity to be proactive rather than reactive.

Palava[5] is an integrated live-work-learn-play city that is spread over 4500 acres. The city offers effortless connectivity due to its location that is in the centre of thane, Navi Mumbai, and Kalyan. The presence of over $60 \%$ open area and thousands of trees offer a better quality of life. In the city of Palava, The 911 service is used to provide emergency response teams. The Palava smart card enables secure access controls and enhanced security which is accompanied by $700+$ CCTV cameras for monitoring along with video surveillance at all public places. Solar Energy is primarily used to augment power supply for common areas and ensures that the city uses an eco-friendly way to generate electricity. Also, Recycled water is used for all needs such as flushing and landscaping. A Net-zero SWM(Solid Waste Management) plants convert waste into manure for landscaping and biogas for electricity. The efficient functioning of public vehicles and the prevention of traffic congestion is also ensured in the city.

With the increasing population, the demand of the urban citizens for basic facilities such as water, energy, infrastructure, and clean environment is increasing correspondingly and the fact that urban resources and infrastructure are already used beyond capacity makes the matter even worse [6]. As a result, we are facing issues such as air pollution, waste management, poor water and electricity supply, aging infrastructure, and resource limitation. In order to overcome these problems cities need to alter their way of functioning and that is where the concept of smart cities comes into the picture. It is now time for India to transform its cities into smart cities to achieve the goal of smart urbanisation. Smart cities make use of Information and Communication Technology to reduce most of the challenges faced due to rapid urbanisation. They offer a suitable lifestyle to citizens by- a. Optimized resource usage. b. Connected and transparent public services. c. Better safety and security d. Improved quality of life. In January 2015, the secretary to the Ministry of Urban Development (MoUD) has stated the Indian government's mission to make 100 smart cities across the country.

Today the urbanisation is escalating rapidly[7] and there is no proper structured waste management system in urban cities. In this paper, the author proposed the solution of the "Sharp Garbage bin", which is an IoT recognizing the model. It will send an alert when the waste containing the compartment is completely filled. Sensors are used to detect the weight, height and abnormal behaviour of dustbin. Sensors data will be used to send an alert. The estimation of dustbin waste and sending the alert signal by SMS is actioned by proper utilisation of the data collected from the sensors. Strain Gauge driver, Smoke sensor, Node MCU, and Arduino Microcontroller are the key components of this system. With the help of this system, waste can be managed properly which would reduce the pollution, the smell of garbage and stop the flood of the waste compartment. The productive use of the Sharp Garbage bin can also help in reducing waste management costs and developing a Smart City.

The author [8] suggested the usage of real-time hydraulic sensor data for controlling and alarming in case of water leakage. This system can help in reducing water wastage and proper use of water in agriculture field. This system is specially developed to solve the water scarcity problem in a country like India. Various Wireless sensor technologies with ICT can be used to solve the problem of water scarcity. Leakage of water can be detected using GPR-Ground Penetrating Radar 
and other electromagnetic sensors. Non-Revenue Water (NRW) can be detected by using pressure sensors at each node. Crop sensors if used properly may help in saving $30 \%$ of water in the crop field. GPRS and RF module can be used to control the flow of water.

As well quoted in [9]; the smart city is a concept for the quality of life of people. Almost all resources are dependent on one another whereas some are completely dependent on energy. So, if there is no source of energy then those resources will be completely exhausted. It's the duty of government to prepare rules and administration to use technology to make proper use of all resources effectively. The smart city is made of three things: competence, cleverness, and convenience. A smart city should be strong interlinked and interdependent. This paper showcases all challenges, features, and policies related to smart cities.

In today's world, cities are the destination home for more than half of the world's population. People are facing environmental pressures and the need for infrastructure is increasing rapidly [10]. Smart technologies can help cities to solve challenges as cities will get smarter and will become more responsive. There are different aspects of technology that could eventually play an important role in urban development. Smart cities add different kinds of digital intelligence to existing urban systems. Digital intelligence can save lives, decrease the level of crime, and resolve the health issue. They can save time, reduce waste, etc. Smart cities also use data and technologies to make productive decisions and improve the quality of life.

In [11], the author has framed the concept of Smart city IoT is a which focuses on urban networking to deal with problems of new generation cities. Automated water supply and traffic management are two important aspects along with connectivity mesh networks to build a smart city. Traffic can be managed by doing big data analysis of regular traffic and using the proper algorithm by machine learning to manage it. Water supply can be managed by using PLC and monitoring the water resources. Automated water management could also be done using sensors and SCADA system.

\section{Working system}

\subsection{Smart Infrastructure}

The infrastructure of a city [12] comprises of housing, sanitation, water supply, sewage, electric power supply, transportation, gas line, Information and Communication Technology (ICT), waste management, street lights, and communication. Smart City Infrastructure brings smartness in the mobility, economy, living, governance, hospital, traffic management, and transportation. In the developing country, city needs immediate urban infrastructure to meet the rise in the population. To meet this increasing demand, smart infrastructure provides a better solution.
Generally in urban cities, all day to day utilities (gas line, power supply, commercial, ICT, etc.) are not underground, first the roads are made and then the utilities are implanted. Dholera, functions differently and smartly; it is the first smart city in India which has all utilities premounted underground. All those utilities are dependent on each other and none of these utilities clash with each other. Post implant; manholes are used when any underground utility needs servicing.

In water pipelines SCADA (Supervised software) sensors are used, which will send data to the ICT service centre. All issues related to communication technology will be solved by the ICT service centre. It is a place that will have access to all sensors' data, CCTV, etc. It will have an artificial intelligent system that will detect alarming situations such as - fire in the building, a vehicle breaking traffic signals, natural calamity and take the initial steps towards the solution of the problem. Also, it has prediction software that predicts the effect of any problem on other regions of Dholera. ICT building is like a command and control centre that integrates the safety and security of the city and makes Dholera a fully Internet-connected city.

The electrical connections and all other utilities required for the smart streets used in Dholera are also underground. They will work on solar energy and have provisions for installing CCTV cameras. If any street light goes off, the information will be sent to the ICT service centre via sensor alarm. Each street light as demonstrated in Fig.2 is connected to the streetlight gateway. 100 gateways are connected to one central software management server.

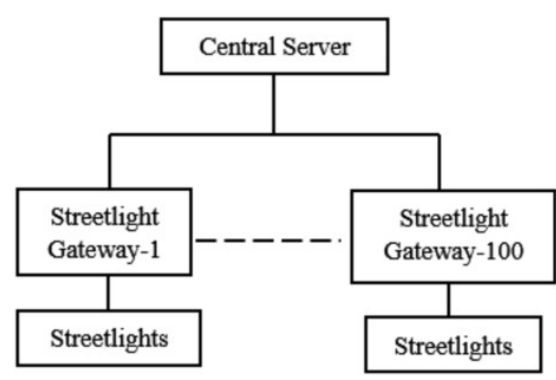

Fig. 2. Streetlight Architecture

Some specialties of Dholera are hospitals with helipads, affordable housing, electric mobility, strong public transport, greenery, and afforestation. In addition to these, it can generate $5000 \mathrm{MW}$ electricity which is the amount of energy required by the Bihar state for a year. It has separate area for economically weaker sections (EWS) households, residential projects, along with commercial projects. Taking the connectivity under consideration - Dholera has 6 lane highway connectivity, seaport, international passenger airport, international cargo airport, metro connectivity within the city. For everyone's ease - all the government work will be done under a single roof i.e. Fig.3 ABCD (Administrative and Business centre for Dholera) building. 


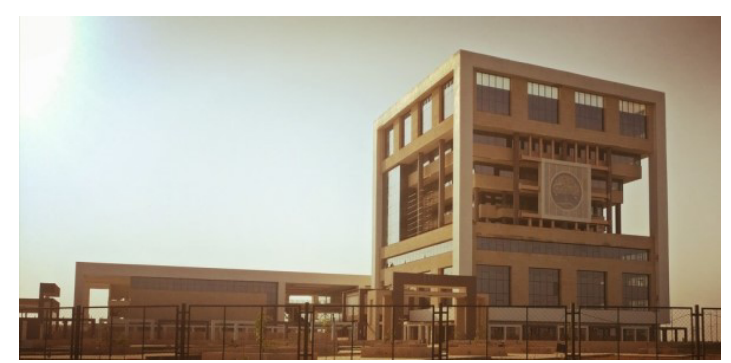

Fig.3. ABCD Building

\subsection{Energy:}

In cities, almost all resources are dependent on one another whereas some are completely dependent on energy. Most of the cities are already facing the energy and environmental challenges which puts 'saving energy and effective use of resources' as one of the main objectives of a smart city. Major cities in India have huge number of vehicles and there is no proper traffic management which causes an excessive amount of pollution which is continuously harming our environment. For example, Delhi the capital of India has unbreathable air due to heavy pollution which has made it India's most polluted city.

The replacement of Electric Vehicles with normal vehicles has a huge impact on protecting the environment. Electric Vehicles are cheaper to run as the cost of electricity is $1 / 3 \mathrm{rd}$ of the petrol. The efficiency of electric vehicles is nearly double because of the electric motor that is used in them in contrast to the combustion engine which is used in fuel vehicles which not only gives less efficiency but also emits harmful gases. Dholera is going to be India's first city with $100 \%$ Electric Vehicles [12].

Dholera has the charging slots for engine, car, and mobile. In addition, bus and walkway shelters are placed to make the mobility of people healthy.

An adequate supply of electricity is the most important need in urban cities. Most of the electricity is generated from coal $(53 \%)$ and it is expected that coal will be completely consumed till 2050 and thus it's the need of the time to switch to the use of renewable sources of energy to generate electricity. Power generation is too costly in India so using solar power is the best alternative to make the environment healthy and liveable. Dholera [12] is in motion for establishing the world's largest solar park with $500 \mathrm{MV}$ and it also has $200 \mathrm{MV}$ wind parks. The Dholera solar park will be developed on a Public-Private Partnership (PPP) model and this will include pay out on works related to the fitting of solar PV panels, inverters and lying of DC cables. But as Dholera is near to sea, the proximity is high the cost is going to increase. The foundation of infrastructure is of very high quality. Generating the power from these alternatives will help tremendously as ultimately it will save energy resources and conserve our environment.
Wind Power and Hydropower are other ways to generate electricity with the use of renewable sources in Dholera. It also has an artificial river in which turbines are installed to be able to generate electricity.

\subsection{Water waste management and water logging:}

The proper planning of Wastewater management and waterlogging ensures that there can't be a flood like situation and all the excess water will be flown from the canal Fig.4 to the sea. Supervisory control and data acquisition (SCADA) sensors are everywhere even in the smaller pipes which will keep pinging to an ICT service centre. SCADA consist of water level indicator, pressure transmitter, flow transmitter, turbidity analyser, and chlorine analyser. For this management, Dholera has an artificial river (canal) that will be made on the basis of hydrology. The water treatment plant is constructed with the latest SCADA and automated technology to provide the intake and outflow of water which will be monitored by the ICT service centre. Different aspects like leakage of pipes all are monitored by sitting at one place by the use of SCADA.

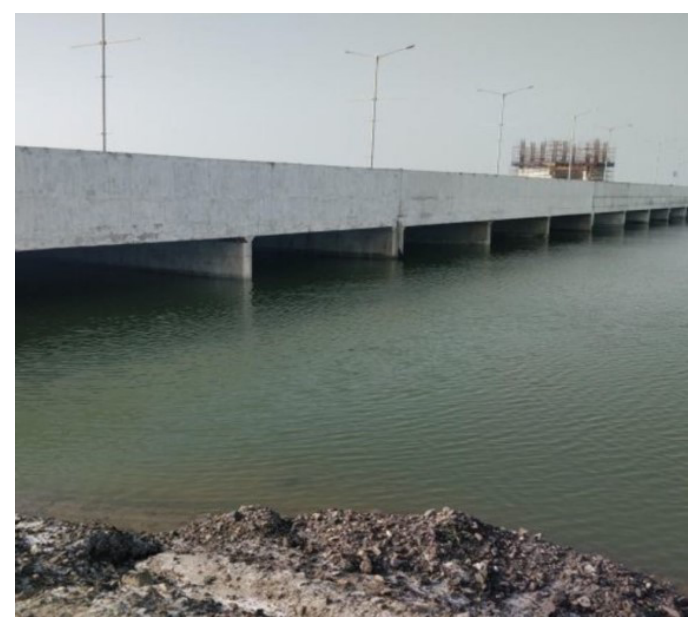

Fig. 4. Artificial river (Canal)

To prevent the harmful effects of wastewater on flora and fauna of the sea, proper treatment of water will be done before dispersing the water in the sea and river.

A water treatment plant has been planned in Dholera. This water treatment plant will provide the basic requirements of potable water to residential, industrial and commercial activation areas. Also, there is recycled water distribution from the sewage treatment plants (STP) as recycled water will reduce the load of potable water demand. The rainwater directly flows into the canal while wastewater first goes through STP before coming to the canal. A barrier is being designed at the end of the canal, which will control the flow of outgoing water from canal to the sea. In Dholera, there are 9 Elevated service reservoirs (ESR) from which 2 are of potable water (ESR P1 and P2) and 7 are of recycling 
water (ESR R1..R7). Reservoir is an artificial lake which is used to store water.

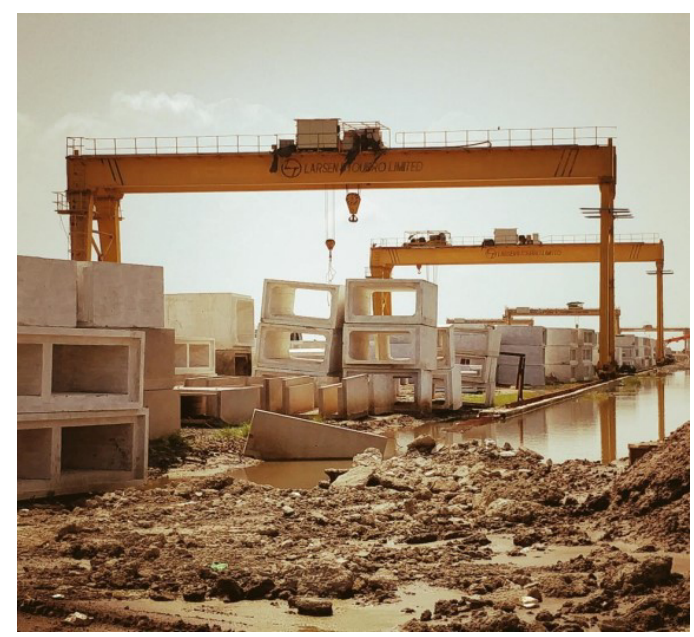

Fig. 5. Drainage system in development

It also has a storm water drainage system as projected in the Fig. 5 that is designed to sustain the rainwater and safely evacuate the rainwater to the ocean. Solid waste management is the key term for waste management; it is the process of collecting and treating solid waste. This system consists of some priorities of water distribution like network efficiency, water loss prevention, improvement in customer service. The water loss Prevention system is been used in Dholera. In it, the water Leakage management system is a central server, which has a database of all pipelines architecture. It receives live water flow data, water pressure data and meter reading. If any anomaly is found in data then it strikes a query to ICT building that water is being leaked at this particular node in the pipeline.

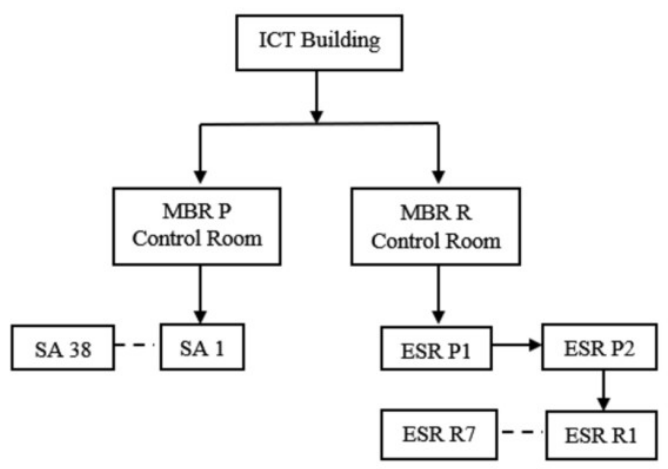

Fig. 6. Overall Instrument Connectivity

In Fig.6 there are a total of 38 service areas (SA), which are connected to the MBR-P (Mass Balancing Reservoir) control room. All ESR are connected to the MBR-R control room and all MBR control rooms are connected to each other. ICT Building controls this whole system.

\section{Conclusion:}

It is only the advancement in technology that has made a lot of human fantasies real. Of so many of its applications, one of them is in the making of cities smarter. One of the reports by the UN [13] suggests that until 2042, the world will need to create 10,000 new cities and as it seems the smarter option is to build smart cities instead. The idea of smart city is around the world for a while now; many countries in the world are already applying this idea such as Brazil, Taiwan, Denmark, US etc.

Many cities are racing towards the journey of smartness; but they are the brownfield cities. When it comes to Greenfield smart city, the count decreases strikingly. Brownfield Cities already have infrastructure built and making any changes to the existing infrastructure is neither simple nor practical. This constraint is nowhere to be found in case of the Greenfield smart cities as they are built from scratch. Greenfield smart cities could be considered as further advancement in the idea of brownfield smart cities.

Dholera SIR, also considered as Prime Minister Shri Narendra Modi's pet project is going to be the first Greenfield smart city of India which is being built on DMIC corridor. It has been selected as the Greenfield site for a number of reasons such as its large areas government land and strong transport links etc.

In the planning of the city, Dholera team has looked at the performance of the best cities in the world in each infrastructure discipline - such as water, waste-water and power. They took the key parameters and benchmarked Dholera against them, designing Dholera to match or improve on what they have achieved. The city of DHOLERA works on the concept of REAPE i.e.Recreation, Education, Awareness, Public art and economic growth. In this paper, we have highlighted the need for the city and its importance to scale it as a big hit.

We have observed that when any ordinary city is transformed into a smart city, the involvement of technology in almost every aspect plays a huge role in generating the unique clusters of data. The technology used in Green fiel-d Smart city is embedded in it from the very beginning. Thus, it wouldn't be wrong when we say that the Dholera which is a Greenfield smart city when developed will result in huge data clusters containing really sensitive data hence a proper plan for risk management becomes the necessity considering the security concerns. Blockchain can play a significant role while addressing these security concerns.

The primary purpose of the paper is to review this future city of India. The majorly explored domains (but not limited to) are:

- $\quad$ City needs 
- The key features of the city in the areas of smart infrastructure, Energy Saving, waste management and waterlogging.

- The working systems of the city.

- The role of technology in solving the problems of the city.

- The application of sensors and SCADA.

\section{References:}

1. https://www.statista.com

2. https://tradingeconomics.com

3. www.timesnow.com

4. https://www.ibm.com/blogs/internet-of-

things/building-smart-city-solutions/

5. https://www.palava.in/

6. India: Surging to a smarter future-PWC.

7. Gopal Kirshna Shyam ; Sunilkumar S. Manvi ; Priyanka Bharti, 2017 2nd International Conference on Computing and Communications Technologies (ICCCT), Smart waste management using Internet-ofThings (IoT),(2007).

8. Aditya Gupta, S. Mishra , Neeraj Dhanraj Bokde , K.D. Kulat, International Journal of Applied Engineering Research, Need of smart water systems in India, 11,(2016).

9. Nallapaneni Manoj Kumar ; Sonali Goel ; Pradeep Kumar Mallick, 2018 Technologies for Smart-City Energy Security and Power (ICSESP), Smart cities in India: Features, policies, current status, and challenges,(2018).

10. Jonathan Woetzel, Jaana Remes, Brodie Boland, Katrina Lv, Suveer Sinha, Gernot Strube, John Means, Jonathan Law, Andres Cadena, and Valerie von der Tann ,Smart cities digital solutions for a more livable future,(2018).

11. Himadri Nath Saha, Supratim Auddy ; Avimita Chatterjee ; Subrata Pal ; Susmit Sarkar ; Rocky Singh , Amrendra Kumar Singh, Priyanshu Sharan , Sohini Banerjee , Ritwik Sarkar, Ankita Maity. 2017 8th Annual Industrial Automation and Electromechanical Engineering Conference (IEMECON), IoT solutions for smart cities,(2017).

12. www.dholerasir.com

13. www.toi.com 